\title{
SENSITIVE DETECTION OF APPLE STEM GROOVING AND APPLE STEM PITTING VIRUSES FROM INFECTED APPLE TREES BY RT-PCR
}

\author{
J. Kummert, V.L.A. Marinho, G. Rufflard, D. Colinet and P. Lepoivre \\ Faculté Universitaire des Sciences Agronomiques \\ Unité de Phytopathologie \\ B-5030, Belgium
}

Keywords: ASGV, ASPV, cDNA amplification, total RNA, ds-RNA, crude extracts

\section{Abstract}

Apple stem grooving virus (ASGV) and apple stem pitting virus (ASPV) occur worldwide in both apple and pear. The reverse transcription - polymerase chain reaction (RT-PCR) techniques became recently available for diagnosis of these fruit tree viruses. These techniques appear more effective than enzyme linked immunosorbent assay (ELISA) when no good quality antisera are available (ASPV), when the virus is present in low concentration, or the detection possible only from specific tissue or at specific time periods from their woody tissue hosts (ASGV).Using degenerate primers designed from the mparison of published sequences for apple chlorotic leaf spot virus (ACLSV), ASGV, and ASPV, amplification products have been obtained from herbaceous host plants and apple trees infected with different isolates of ASGV and ASPV. Their sequencing allowed the design of specific primers for the detection of these viruses in apple trees all year long from leaves or bark of annual shoots. With a first generation of specific primers, the quality of template viral RNA preparations from these woody hosts has been the limiting factor for a reliable detection of these viruses, in these conditions ds-RNA preparations proved to be the best target for sensitive and reproducible detection of virus infection. With a second generation of specific primers (for ASGV) exhibiting better characteristics and used in combination with more stable enzymes for the reverse transcription step, and with more stringent conditions for amplification (higher cycling temperature), reliable results can be obtained directly from diluted crude extracts from the same woody material.

\section{Introduction}

Apple stem grooving virus (ASGV) and apple stem pitting virus (ASPV) are important latent viruses with elongated particles infecting pome fruit trees (apple and pear). Although .tent in commercial apple and pear cultivars, both viruses induce symptoms when grafted on specific Malus species which are currently used as biological indicators.

The biological indexing by grafting on woody indicators constitutes the "baseline" tests for the certification of fruit trees planting material, but appears cumbersome, lengthy and expensive to perform (time. space and qualified manpower required) and does not respond to the actual constraints of production of certified material in a world where the volume, the distances, and the rapidity of the exchange of material have raised dramatically. In these conditions, reliable and rapid detection protocols for latent viruses is thus important in the implementation of sanitary control of multiplication material of fruit trees.

Enzyme linked immunosorbent assays (ELISA) can be used to detect ASGV in crude extracts of herbaceous hosts and in leaves of woody plants, but is inappropriate to detect the virus present in low concentrations in infected trees in orchards, i.e. during the summer or in dormant woody tissues. For ASPV, good quality commercial antisera for use in ELISA tests are not available so far.

We had previously developed RT-PCR protocols for amplification of viral sequences from total RNA preparations of either apple chlorotic leaf spot virus (ACLSV), ASGV 
and/or ASPV, by using degenerate primers (Kummert et al., 1997). These degenerate primers allowed reliable amplification of virus specific sequences from transcripts of total RNA preparations from herbaceous host plants grown in the greenhouse and from leaves of some virus-infected apple-trees from the orchard, but only during spring. Meanwhile, cloning and sequencing of these amplification products allowed to define more specific primers for RT-PCR detection of various isolates of these viruses in apple trees. This paper reports the results obtained for the detection of ASGV and ASPV infection in different extracts from leaves or bark tissues of apple trees at different times during the year.

\section{Materials and methods}

\subsection{Virus-infected material}

Reference isolates for ASGV (10311, 10391, 10771 and G 77, originating from the Research Station of Gorsem, and PV 199 obtained from DSM, Braunschweig, Germany) were maintained in the greenhouse in Chenopodium quinoa and Nicotiana glutinosa.

Reference isolates for ASPV were maintained in the greenhouse on N. occidentalis 27B and $N$. obliqua. ASPV-J and 3536 were received from Dr. Jelkmann (BBA-Dossenheim, Germany) and Dr. Leone (IPO/DLO, Wageningen, The Netherlands), respectively. The other isolates were obtained from material received from the Research Station of Gorsem, Belgium.

Eleven infected apple trees prepared by the Research Station of Gorsem were grown in Gembloux and we have access to a large collection of virus-infected apple trees in one field of the Research Station of Gorsem. The infected apple trees used for this study are more generally infected with more than one virus, and contain either ACLSV, ASGV and/or ASPV. Several trees also induce Spy epinasty disease on this indicator.

\subsection{Nucleic acid extraction}

The standard protocol for extraction of total RNA from infected plants relies on the use of Tripure $^{\mathrm{TM}}$ isolation reagent (Boehringer) according to manufacturer's instructions. One hundred mg of plant tissue were frozen in liquid nitrogen and then homogenized in Tripure reagent by Ultra-Turrax at maximum speed for $30 \mathrm{sec}$. After centrifugation, the nucleic acids were recovered from the aqueous phase by precipitation in isopropanol.

For extraction of total RNA preparations from woody samples, several methods have been compared, which did not contain chaotropic salts like guanidine isothiocyanate, as it is the case for Tripure ${ }^{\mathrm{TM}}$ and other similar reagents contained in nucleic acid extraction kits. They were applied to samples of $1 \mathrm{~g}$ of tissue, frozen in liquid nitrogen and ground to a fi powder using mortar and pestle. Two protocols used potassium acetate instead of phenol extraction (Astruc et al., 1996; Spiegel et al., 1996). One used hot CTAB as extraction buffer, followed by chloroform-isoamyl alcohol extraction and $\mathrm{LiCl}$ precipitation (Chang et al., 1993), and the last used Tris, NaCl, EDTA extraction buffer, phenol-chloroform-isoamyl alcohol extraction and isopropanol $+\mathrm{LiCl}$ precipitation (Bugos et al., 1995).

Double-stranded RNA (ds-RNA) preparations were initially obtained from $20 \mathrm{~g}$ of leaf or bark tissues from apple trees, according to the method of Valverde (1990). This protocol was later adapted for working with samples of only 0.5 to $1 \mathrm{~g}$ of plant material, the final dsRNA pellet being resuspended in $10 \mu \mathrm{l}$ of DEPC-treated water.

\subsection{Preparation of crude extracts for RT-PCR}

About $0.1 \mathrm{~g}$ of plant tissue were ground in $2 \mathrm{ml}$ of TE buffer $\mathrm{pH}$ 8.0. After clarification for $10 \mathrm{~min}$ at $10,000 \mathrm{~g}, 50 \mu \mathrm{l}$ were transferred to PCR microtubes and left for $1 \mathrm{~h}$ on melting ice. The crude extracts were then removed, the tube rinsed with TE buffer, and then replaced by $50 \mu$ of RT-PCR mix. Alternatively $1 \mu$ of the same clarified crude sap (with or without further dilution) was directly put in the RT-PCR mix. 
Single stranded cDNA was synthesized from 1 to $2 \mu \mathrm{g}$ of total RNA preparations from plant tissues, or 1 to $5 \mu \mathrm{l}$ of dsRNA preparations, using the Expand ${ }^{\mathrm{TM}}$ reverse transcriptase (Boehringer) with oligo-dT primers. After 5 fold dilution, $5 \mu$ l of cDNA preparations thus obtained were used for amplification in a total volume of $50 \mu$ l of PCR buffer $(10 \mathrm{mM}$ Tris$\mathrm{HCl} \mathrm{pH} \mathrm{9.0,50} \mathrm{mM} \mathrm{KCl,} 0.1 \%$ Triton X-100), containing $1.5 \mathrm{mM} \mathrm{MgCl}_{2}, 200 \mathrm{mM}$ each dATP, dCTP, dGTP, dTTP, $0.4 \mu \mathrm{M}$ of each upstream and downstream primers and 1 unit of Taq DNA polymerase (Boehringer). Later, the $\operatorname{Titan}^{\mathrm{TM}}$ one tube RT-PCR system from Boehringer was used according to manufacturer's instructions. Thermal cycling was performed in a Triothermoblock cycler (Biometra, Göttingen) or a PTC 200 cycler from MJ Research.

The PCR was performed after a denaturation step of $5 \mathrm{~min}$ at $94^{\circ} \mathrm{C}$. Thirty to 35 cycles were applied, consisting in template denaturation at $94^{\circ} \mathrm{C}$ for $30 \mathrm{sec}$, primer annealing at 48 to $62^{\circ} \mathrm{C}$ (depending on the primers) for $1 \mathrm{~min}$, and DNA synthesis at $72^{\circ} \mathrm{C}$ for $2 \mathrm{~min}$. A final elongation step of $15 \mathrm{~min}$ at $72^{\circ} \mathrm{C}$ was performed at the end of the 30 or 35 cycles, and $10 \mu \mathrm{l}$ of the reaction mixtures analyzed by electrophoresis in $1 \%$ agarose gel stained with ethidium bromide (Sambrook et al., 1989), in TAE buffer.

\section{Results and discussion}

\subsection{Design of primers}

Amplification products corresponding to part of the $3^{\prime}$ end of the RNA polymerase gene, and obtained with degenerate primers from reverse transcribed total RNA preparations from leaves of herbaceous hosts or apple-trees infected with ASGV or ASPV isolates (Kummert et al., 1997), have been cloned and sequenced. The alignment of these sequences, and those published for ASGV (Yoshikawa et al., 1992) or ASPV (Jelkmann, 1994), allowed the selection of consensus sequences for primers design.

Primer pairs ASGV1F-ASGV1R and ASGV4F-ASGV4R have been successively retained for use in RT-PCR detection of infection with ASGV:

ASGV1F = 5'-GARGCWAAAGCTGGYCAA-3' (nt 3925-3942)

ASGV1R = 5'-YACCTCTTCYACWGCAGT-3' (nt 4485-4468)

ASGV4F $=5$ '-GTTCACTGAGGCAAAAGCTGGTC-3'(nt 3918-3940)

ASGV4R = 5'-CTTCCGTACCTCTTCCACAGCAG-3' (nt 4491-4469)

For ASPV, four primers were also selected for development of RT-PCR detection tests. These primers are:

ASPV1F $=$ 5'-CTTCATGAAGTCGCAACTTTGCACCA-3' (nt 5691-5716)

ASPV1R = 5'-GCYTCYYTHCCATTVAGATCATACCT-3' (nt 6176-6151)

ASPV2F $=5$ '-TCAACATTCWGTNYTKGC-3' (nt 5769-5787)

ASPV2R = 5'-TGAACAAGAANGTGCTBGC-3' (nt 6118-6100)

Reverse transcription and amplification steps have been optimized for the different specific primers selected, for use with extracts of apple tree material consisting in total RNA or ds-RNA preparations, and crude sap.

\subsection{Priming of the reverse transcription step}

There are three approaches to prime the reverse transcription: (1) oligo dT which binds to endogenous poly-A tail at the $3^{\prime}$ end of eukaryotic messenger RNA and a number of RNA viruses, (2) random hexanucleotides which bind to RNA template at any complementary site, and (3) specific oligonucleotide sequences chosen to selectively prime the RNA sequence. 
As the genomic RNA of ASGV and ASPV contains a 3' end poly-A tail, all the work done previously used oligo dT priming for the reverse transcription step. As the sequences targeted by our different primers are located at more then 3000 nucleotides from the $3^{\prime}$ end of the viral genome, we envisaged to compare the results obtained from transcripts of the same total RNA preparations by using the 3 priming strategies with the Titan $\square$ one tube RT-PCR system. Higher or more reliable amplification signals were always observed for both viruses when the specific reverse primer for DNA amplification was also used for the RT step. Priming with random hexanucleotide always gave very low amplifications.

\subsection{Preparation of template RNA for RT-PCR}

Standard protocol consisted in the use of Tripure isolation reagent (Boehringer) applied to $100 \mathrm{mg}$ of leaf tissue. Like other kits, available for total nucleic acid or RNA extraction, this system relies on use of chaotropic agents and phenol extraction.

Specific amplification products obtained with primers ASGV1F-ASGV1R for ASGV, and the different primer pairs selected for ASPV, were easily and reliably visualized in ethidium bromide stained agarose gels from ASGV- or ASPV- infected herbaceous host plants. However, total RNA preparations obtained from leaf or bark material harvested on apple trees from the orchard did not always give rise to visible bands of amplification products. After southern blotting and hybridization with specific digoxigenin labeled probes, expected amplification products can be detected, but this technique is technically demanding and not adequate for routine detection of virus infection.

It is actually well documented that some plant tissues are recalcitrant to RNA extraction with chaotropic agents (Bugos et al., 1995), giving low yields and low A260/A280 ratios. indicating the presence of contaminants.

Four protocols avoiding the use of chaotropic agents. and/or toxic organic solvents. have been comparatively tested for the extraction of total nucleic acids or RNA from woody tissues (see Material and methods).

All these protocols were used as described by their respective authors, but adapted to comparable samples of $1 \mathrm{~g}$ of tissue, frozen in liquid nitrogen and ground to a fine powder using mortar and pestle. Those protocols which do not include $\mathrm{LiCl}$ precipitation were used as originally described. and with a supplementary $\mathrm{LiCl}$ precipitation step. The final RVA preparations were resuspended in $10 \mu \mathrm{l}$ of DEPC treated water. After measure of their absorbance at 260 and $280 \mathrm{~nm}$ and estimation of the total RNA concentrations, $1-2 \mu \mathrm{g}$ of all preparations were used for RT-PCR amplifications using the Titan ${ }^{\mathrm{TM}}$ one tube RT-PCR system from Boehringer.

Total RNA preparations obtained by the method of Bugos et al. (1995) showed the best A260-A280 ratios for a great majority of the samples, and gave rise to more reliable amplifications, as visualized in ethidium bromide stained agarose gel. This method has thus been retained for the RT-PCR detection test of a large number of apple trees from the collection of "virus infected" trees in the orchard of the Research Station of Gorsem.

\subsection{RT-PCR on ds-RNA preparations}

Previous work with degenerate primers (Kummert et al., 1997) had shown that RT-PCR amplification products could be obtained occasionally from ds-RNA preparations from bark tissue (ASPV), or bark and leaf tissue (ASGV) of shoots of apple trees. Preliminary experiments conducted with the different selected specific primers on ds-RNA preparations obtained from $20 \mathrm{~g}$ of tissue, by using Expand ${ }^{\mathrm{TM}}$ Reverse transcriptase (Boehringer) with oligo dT primer for first strand cDNA synthesis and Taq DNA polymerase for PCR amplification, showed positive results for sensitive detection of ASGV and ASPV in apple trees. From there, we have developed a ds-RNA extraction protocol working from 0.5 to $1 \mathrm{~g}$ of plant tissue to be used for virus specific amplification with the Titan ${ }^{\mathrm{TM}}$ one tube RT-PCR system (Boehringer). 
Figure 1 shows the results obtained for ds-RNA preparations obtained from bark or leaf tissue from 3 ASPV-infected trees. About 1/10th of the ds-RNA solution obtained from $1 \mathrm{~g}$ of tissue has been used for Titan ${ }^{\mathrm{TM}}$ one tube RT-PCR amplification with primers ASPV1R and ASPV2F. Reverse transcription was performed at $50^{\circ} \mathrm{C}$ for $30 \mathrm{~min}$ and immediately followed by amplification for 5 cycles at primers annealing temperature of $42{ }^{\circ} \mathrm{C}$, and 30 cycles at $50^{\circ} \mathrm{C}$. After electrophoresis in ethidium bromide stained agarose gels, amplification products were observed, for all the ds-RNA preparations tested, but some light bands are poorly visible on the photo.

Experiments conducted during the whole year on several infected trees have shown that ds-RNA preparations constitute good target for RT-PCR detection of infections by ACLSV, ASGV and/or ASPV in apple trees. This approach proved very reliable when applied to dormant woody tissue, while other tests are not possible or unreliable with that material.

\subsection{Direct RT-PCR on crude extracts}

Although the antiserum used for detection of ASGV by ELISA did not work in immunocapture RT-PCR, and no good ASPV antiserum is available, we have considered the use of RT-PCR on crude extracts for both viruses. For this, we have tried to use direct binding of crude sap on the wall of the tubes, followed by washes before RT-PCR amplification, and deposit of diluted crude sap directly in the RT-PCR mix.

In these conditions, specific amplifications clearly visible in ethidium bromide stained - arose gels were obtained from crude sap of ASGV infected leaves of C. quinoa or $N$. glutinosa with primers ASGV1F-ASGV1R (Titan ${ }^{\mathrm{TM}}$ one tube RT-PCR system; 30 cycles with primers annealing temperature of $52^{\mathrm{TM}} \mathrm{C}$ ). For crude extracts of leaves or bark tissue of shoots of apple trees, reproducible results were only obtained with the selected primers ASGV4F-ASGV4R used with a temperature of $62^{\circ} \mathrm{C}$ for primers annealing, the other parameters being constant. Figure 2 shows the results of one experiment using primers ASGV4F-ASGV4R; in this case. the direct binding used $50 \mu$ of clarified crude sap diluted $1 / 20$, or $1 \mu \mathrm{l}$ of crude sap diluted $1 / 200$ was put in the RT-PCR mix.

For ASGV, different apple trees which appeared previously positive in RT-PCR tests conducted with RNA or ds-RNA preparations have been tested by using crude extracts with Titan $^{\mathrm{TM}}$ one tube RT-PCR system and primers ASGV4F-ASGV4R, and all were also positive in these conditions. The final dilution of the crude sap used was most generally 1/200. but positive results were also obtained with dilutions of $1 / 20$ or 1/2000. Although reproducible results have been obtained with the Titan one tube RT-PCR system, no amplification was observed from crude sap of comparable apple plant material when using the classical two steps RT-PCR systems or the one step system using Tth enzyme for both DT and PCR steps.

For ASPV, for which the available primers are shorter. and have thus less good characteristics, no positive results could be obtained so far with crude extracts from apple trees.

\section{Conclusions}

Specific primers targeting fragments ( 350 to $57+\mathrm{nt}$ ) located near the $3^{\prime}$ end of the gene coding for the viral RNA polymerase have been selected for the RT-PCR detection of ASGV and ASPV infections in apples trees.

For ASPV, sensitive and reliable results are obtained from total RNA preparations from leaves or bark tissues harvested on apple trees from the orchard.

For ASGV, the higher homology existing between the isolates sequenced allows the design of primers with better conformational properties, giving comparable results directly from crude extracts from apple trees.

For both viruses, the best available technique for RT-PCR diagnosis of infection is actually validated on a great number of apple trees from the orchards. 
This work was supported by the Ministry of Agriculture, DG VI, Belgium. V.L.A. Marinho is a doctoral fellow of EMBRAPA (Brazilian Enterprise for Agricultural Research).

\section{References}

Astruc N., Marcos J.F., Macquaire G., Candresse T., and Pallas V., 1996. Studies on the diagnosis of hop stunt viroid in fruit trees: Identification of new hosts and application of a nucleic acid extraction procedure based on non-organic solvents. Eur. J. Plant Pathol. 102: 837-846.

Bugos R.C., Chiang V.L., Zhang X.H., Campbell E.R., Podila G.K., and Campbell W.H., 1995. RNA isolation from plant tissues recalcitrant to extraction in guanidine. Biotechniques 19: 734-737.

Chang S., Puryear J., and Cairney J., 1993. A simple and efficient method for isolating RNA from pine trees. Plant Mol. Biol. Reporter 11: 113-116.

Jelkmann W., 1994. Nucleotide sequence of apple stem pitting virus and of the coat protein gene of a similar virus from pear associated with vein yellows disease and their relationship with potex- and carlavirus. J. Gen. Virol. 75: 1535-1542.

Kummert J., Rufflard G., and de Almeida Marinho V., 1997. Use of degenerate primers for RT-PCR detection of apple and pear tree viruses. In: C. Manceau and J. Spak (eds). Advances in the Detection of Plant Pathogens by Polymerase Chain Reaction Commission of the European Communities, Luxembourg (pp. 34-48).

Sambrook J., Fritsch E.F., and Maniatis T., 1989. Molecular cloning: A laboratory manual. New-York, Cold Spring Harbor Laboratory.

Spiegel S., Scott S.W., Bowman-Vance V., Tam Y., Galiakparov N.N., and Rosner A., 1996. Improved detection of prunus necrotic ringspot virus by the polymerase chain reaction. Eur. J. Plant Pathol. 102: 681-686.

Valverde R.A., Nameth S.T., and Jordan R.L., 1990. Analysis of double-stranded RNA for plant virus diagnosis. Plant Dis. 74: 255-258.

Yoshikawa N., Sasaki E., Kato M., and Takahashi T., 1992. The nucleotide sequence of apple stem grooving capillovirus genome. Virology 191: 98-105. 


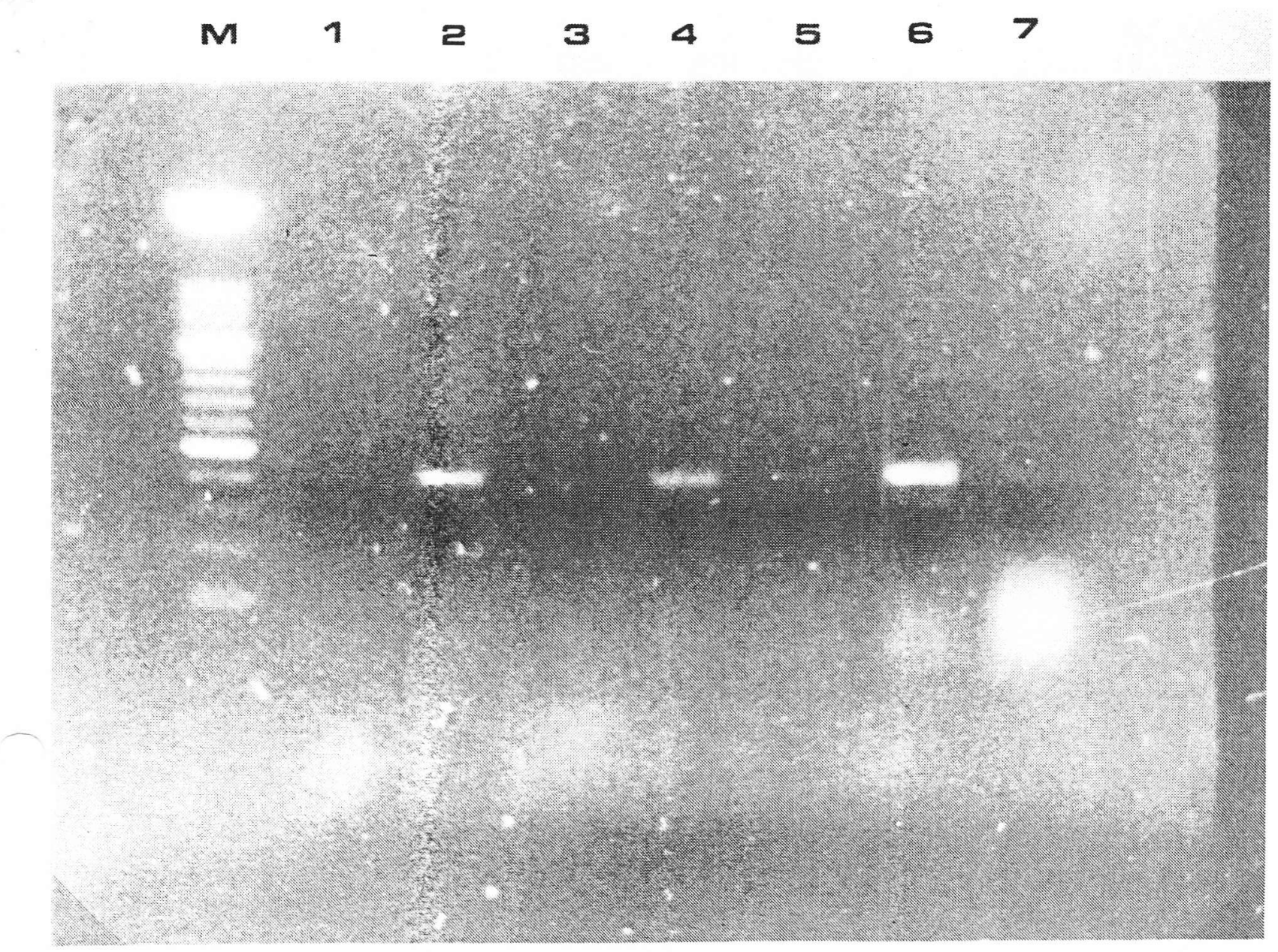

Figure 1 - Agarose gel electrophoretic analysis of $\operatorname{Titan}^{\mathrm{TM}}$ one tube RT-PCR amplification products obtained with primers ASPV1R-ASPV2F from ds-RNA preparations of apple trees LP680 (bark; 1). TH 1386 (bark; 2). TH 1385 (bark; 3), T 3058 (leaf; 4, bark; 5). Positive control consisted in total RN.A preparation from ASPV infected $N$. occidentalis (6); $7=$ total RNA preparations from leaves of apple tree T $3058 ; \mathrm{M}=$ molecular weight marker (100 bp, Boehringer; lower heary band corresponds to $500 \mathrm{bp}$ ). 

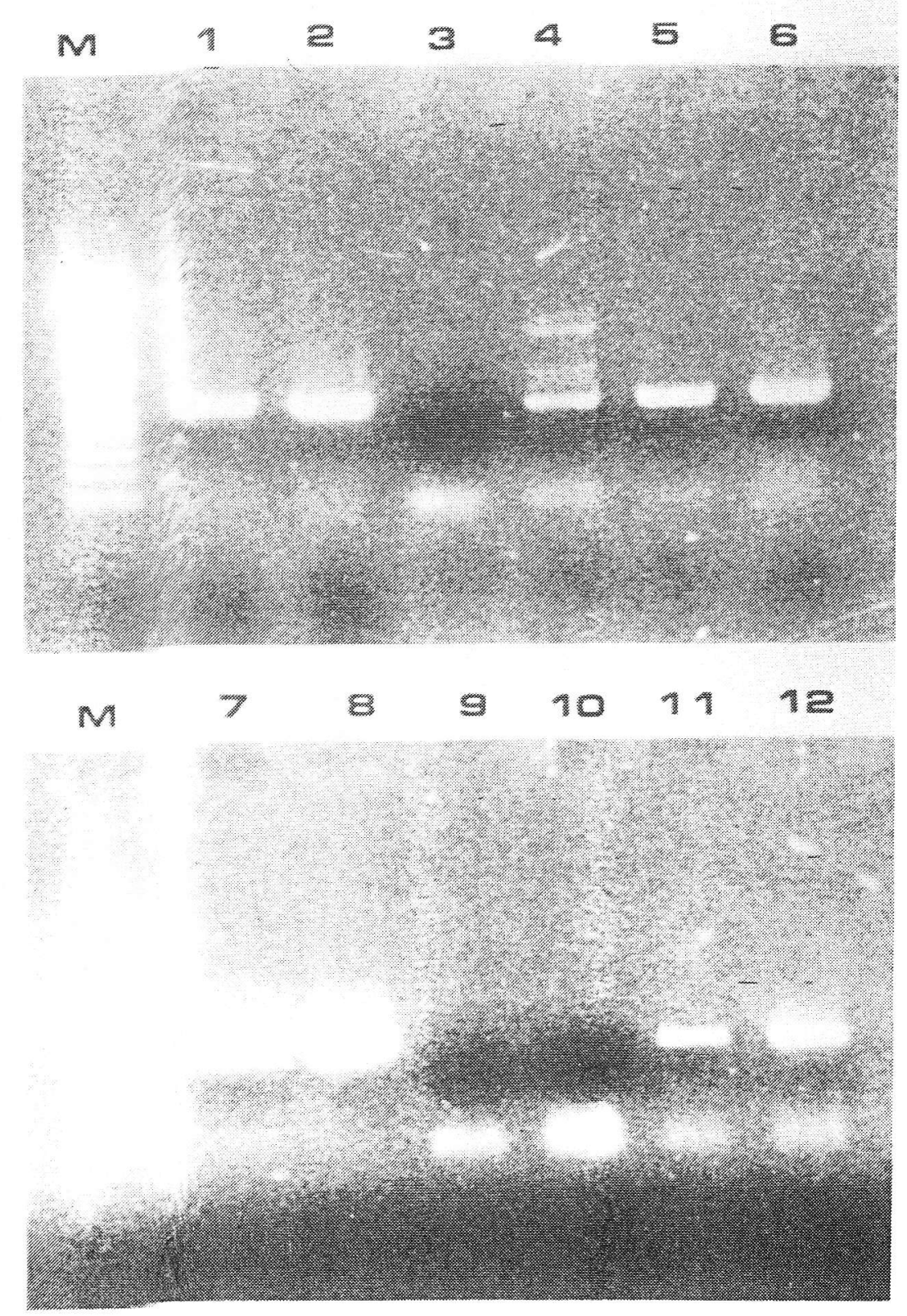

Figure 2 - Agarose gel el-ctrophoretic analysis of $\operatorname{Titan}^{\mathrm{TM}}$ one tube RT-PCR amplification products obtained with puners ASGV4F-ASGV4R from crude extracts of healthy (3,9) or ASGV infected leaves of I glutinosa (isolate 10311:1.7: isolate 10391:2,8) or from bark 0 . annual shoots from apple uee $10291(4,11)$ or $10392(5,12)$, taken in January in the field in Gembloux. Positive contr.! (lane 6) consists in total RVA preparation of ASGV infected C. quinoa leaves (isolate 1::11); negative control (lane 10) corresponds to RT-PCR mix without plant sap or RNA : reparation. Lanes 1-5: direct binding (50 $\mathrm{g}$ of clarified crude sap diluted 1:20 in TE buffer. :cubated for $1 \mathrm{~h}$ at $0^{\circ} \mathrm{C}$, and withdrawn before RT-PCR). Lanes 712: $1 \mu$ of clarified cru sap diluted 1:200, directly put in the RT-PCR mix. Lane M = molecular weight marker : $00 \mathrm{bp}$. Boehringer; lower heavy band corresponds to $500 \mathrm{bp}$ ). 